\title{
DEVELOPMENT AND VALIDATION OF A FAST AND SENSITIVE UHPLC-PDA METHOD FOR THE QUANTIFICATION OF URSOLIC ACID IN POLY(L-LACTIC ACID) NANOCAPSULES
}

\author{
BRUNA CARLETTO ${ }^{1}$, AMANDA MARTINEZ LYRA ${ }^{1}$, ADRIANA YURIKO KOGA ${ }^{1}$, ANDRESSA NOVATSKI ${ }^{2}$, \\ RUBIANA MARA MAINARDES ${ }^{3}$, LEANDRO CAVALCANTE LIPINSKI ${ }^{2}$, PAULO VITOR FARAGO ${ }^{1 *}$
}

\begin{abstract}
${ }^{1}$ Postgraduate Program in Pharmaceutical Sciences, State University of Ponta Grossa, Ponta Grossa, Brazil. ${ }^{2}$ Department of Medicine, Postgraduate Program in Health Sciences, State University of Ponta Grossa, Ponta Grossa, Brazil. ${ }^{3}$ Postgraduate Program in Pharmaceutical Sciences, State University of Midwestern Parana, Guarapuava, Brazil. Email: pvfarago@gmail.com
\end{abstract}

Received: 09 July 2020, Revised and Accepted: 19 August 2020

ABSTRACT

Objective: The aim of the present study is to develop and validation of a ultra-high performance liquid chromatography (UHPLC) method to determine the ursolic acid content and its encapsulation efficiency (EE) in lipid-core nanocapsules prepared from poly (L-lactic acid).

Methods: A simple UHPLC-PDA method was developed and validated for the quantitative determination of ursolic acid in poly(L-lactic acid) nanocapsules. The chromatographic conditions used were: RP-C18 column, isocratic mobile phase containing acetonitrile:water ( $92: 8$, v/v), flow rate of $0.8 \mathrm{ml} / \mathrm{min}$, column temperature of $50^{\circ} \mathrm{C}$, and detection at $203 \mathrm{~nm}$. The following parameters were evaluated: Specificity, linearity, limits of detection and quantification, precision, accuracy, and robustness.

Results: The method was specific to the ursolic acid and linear ( $\mathrm{r}=0.9998)$ in the range of $10-100 \mu \mathrm{g} / \mathrm{ml}$. The limits of detection and quantification were 1.35 and $4.10 \mu \mathrm{g} / \mathrm{ml}$, respectively. The precision was demonstrated by a relative standard deviation less than $2 \%$. Adequate accuracy ( $98.35 \% \pm 0.82)$ was obtained. Changes in flow rate, mobile phase, and column temperature did not significantly alter the peak area and the retention time of the ursolic acid. The mean EE was $99.89 \%$.

Conclusion: The method proved to be fast, sensitive, and simple for quantifying ursolic acid in nanocapsules and was successfully used for determining the EE.

Keywords: Analytical development, Drug quantification, Lipid-core nanocapsules, Pentacyclic triterpenoid, Quality assurance, Quality control.

(c) 2020 The Authors. Published by Innovare Academic Sciences Pvt Ltd. This is an open access article under the CC BY license (http://creativecommons. org/licenses/by/4. 0/) DOI: http://dx.doi.org/10.22159/ajpcr.2020.v13i9.38993

\section{INTRODUCTION}

Pentacyclic triterpenoids are phytochemicals widely distributed in nature and ursolic acid (3ß-hydroxy-urs-12-en-28-oic) (UA) is one of their main representatives [1]. It is a white crystalline solid and shows a melting point between 285 and $288^{\circ} \mathrm{C}$ with a molecular weight of $456.68 \mathrm{~g} / \mathrm{mol}$ and molecular formula $\mathrm{C}_{30} \mathrm{H}_{48} \mathrm{O}_{3}$ [2]. UA is usually found in human diet [3] and has a wide range of biological activities, such as the antioxidant effect [4], the anti-obesity and muscle synthesis properties [5], the hepatoprotective potential [6], the blood sugar-lowering effect [7], the neuroprotective potential [8], the antiinflammatory activity [9], and the antitumor properties $[10,11]$

In spite of this pharmacotherapeutic potential, some limitations can be related to the UA use due to its low aqueous solubility and its reduced permeability through biological membranes, which decrease its absolute bioavailability to about $8 \%$ [12] and lead to a classification as a class IV drug by the biopharmaceutical classification system. For this reason, strategies to overcome these limitations have been widely studied mainly based on nanotechnology $[13,14]$. In brief, the aim of these approaches was to develop formulations with efficacy and safety that might guarantee at the same time improved solubility, higher bioavailability, and a controlled release pattern for this drug [15]. However, nanoparticles require extensive characterization, including the mandatory determination of the drug content and the encapsulation efficiency (EE) to achieve the expected clinical effect while assuring suitable pharmacokinetic and pharmacodynamic properties when administered in vivo $[16,17]$. Thus, a validated method that is able of quantifying the drug loading in nanoformulation is essential during the research and development process.
In this scenario, some analytical methods were previously described for the UA quantification, mainly in botanicals $[18,19]$ and biological samples as plasma $[20,21]$. Concerning to the methods developed for drug delivery systems, these strategies were typically based on highperformance liquid chromatography [22-24]. Therefore, to the best of our knowledge, no previous paper was devoted to validate an analytical method for the UA determination in lipid-core nanocapsules using ultra-high-performance liquid chromatography (UHPLC). UHPLC has currently attracted great interest from the pharmaceutical industry due to its ability to achieve maximum use of chromatographic principles, to have superior features in terms of resolution, sensitivity, and efficiency, and to decrease the consumption of solvents and other reagents [25].

In this context, the present paper describes the development and the validation of a UHPLC-PDA method for determining the UA content and its EE in lipid-core nanocapsules prepared from poly(L-lactic acid) (PLA).

\section{METHODS}

Reagents and chemicals

Ursolic acid (UA) 98\% pure was purchased of Natural Field BioTechnique (Xi'an, China). Methanol HPLC grade (Research Hexis, Phillipsburg, NJ, USA), acetone P.A. (Synth, Diadema, Brazil), acetonitrile HPLC grade (J.T. Baker, Phillipsburg, NJ, USA), L-lactic acid 90\% pure (Vetec, Duque de Caxias, Brazil), and chloroform P.A. (Vetec, Duque de Caxias, Brazil) were used as received. The water was purified using a Milli-Q Plus system (Millipore, Burlington, MA, USA).

\section{Equipment}

A Shimadzu UHPLC system (Nexera X2, Kyoto, Japan) equipped with a SPD-M20A PDA detector, a DGU-20A5RA degasser, a 
LC-30AD pump, a SIL-30AC autosampler, a CTO-20A oven, and a CBM-20A communicator module was used for the analytical method development. The LabSolutions software version 5.73 was used for the acquisition, the analysis and the data generation. The UHPLC analysis was performed using a C18 Shim-pack XR-ODS III reverse phase column (Kyoto, Japan) with a $2.2 \mu \mathrm{m}$ particle size coupled to the pre-column.

\section{Chromatographic conditions}

The mobile phase consisted of a mixture of acetonitrile and water $(92: 8, \mathrm{v} / \mathrm{v})$ with a flow rate of $0.80 \mathrm{ml} / \mathrm{min}$. The elution was performed in an isocratic mode. The injection volume was $10 \mu$ l. The analyses were carried out at a temperature of $50^{\circ} \mathrm{C}$, the PDA detector wavelength was set at $203 \mathrm{~nm}$, and the running time was $2.1 \mathrm{~min}$.

\section{Preparation of standards and samples}

The standard UA stock solution was prepared in methanol at $500 \mu \mathrm{g} / \mathrm{ml}$. Dilutions were performed to obtain solutions with a concentration between 10 and $100 \mu \mathrm{g} / \mathrm{ml}$. The UA samples corresponded to the supernatant obtained after the ultracentrifugation of UA-loaded nanocapsules, as described in the method applicability section. Standards and samples were suitably diluted in methanol to obtain the desired concentration. These solutions were filtered through a polytetrafluoroethylene filter (PTFE, Chromafil Xtra, $0.2 \mu \mathrm{m} \times 13 \mathrm{~mm}$, Macherey-Nagel, Düren, Germany) before injection.

\section{Validation method}

The validation of the analytical method by UHPLC-PDA was performed according to the criteria proposed by the International Conference on Harmonisation of Technical Requirements for the Registration of Pharmaceuticals for Human Use [26]. The following characteristics were considered: Specificity, linearity, limit of detection (LOD), limit of quantification (LOQ), precision, accuracy, and robustness. Specificity was determined by analyzing the chromatograms of UAloaded nanocapsules compared to those obtained from non-loaded formulations.

The linearity was investigated by the linear regression using the leastsquares method from three authentic analytical curves obtained at 10 ; 30; 40; 60; 70; 80; and $100 \mu \mathrm{g} / \mathrm{ml}$. The slope and other parameters of the analytical curves were calculated by the linear regression and the analysis of variance (ANOVA). The residue analysis was carried out using Statistica 8.0 (StatSoft, Tulsa, OK, USA). The LOD (Eq.1) and the LOQ (Eq.2) were determined using the following equations as recommended by ICH [26].

$$
\begin{aligned}
& L O D=\frac{3.3 \times S D}{S} \\
& L O Q=\frac{10 \times S D}{S}
\end{aligned}
$$

where $\sigma$ is the standard deviation (SD) from the response and $S$ is the slope of the mean calibration curve.

Precision was assessed at two different levels: Repeatability (intraday precision) and intermediate precision (interday precision). These parameters were investigated at $60 \mu \mathrm{g} / \mathrm{ml}$ in sextuplicate and at 20; 50; and $90 \mu \mathrm{g} / \mathrm{ml}$ in triplicate. The results were expressed in terms of SD and relative SD (RSD) (DPR). Accuracy was assessed by recovery analysis in which a known amount of UA $(15 \mu \mathrm{g})$ was added in triplicate to the solutions of $10.0 ; 40.0$; and $80.0 \mu \mathrm{g} / \mathrm{ml}$. The accuracy of the method was calculated by the percentage ratio between the experimental concentration and the theoretical concentration, and the results expressed as a percentage of the recovery. Robustness was evaluated in the samples at $60 \mu \mathrm{g} / \mathrm{ml}$ by intentionally varying the flow rate to 0.75 and $0.85 \mathrm{ml} / \mathrm{min}$, and the concentration of the acetonitrile:water mobile phase to $91: 9(\mathrm{v} / \mathrm{v})$ and 93:7 (v/v).
Method applicability: Synthesis of PLA, preparation of ursolic acid-loaded lipid-core nanocapsules, and determination of EE The preparation of PLA was carried out through the polycondensation reaction of L-lactic acid $[27,28]$. Briefly, $200 \mathrm{ml}$ of L-lactic acid (90\% w/v) were added into a round bottom flask and a distillation system was then connected. The flask was kept into an oil bath at $180^{\circ} \mathrm{C}$ for $8 \mathrm{~h}$ under magnetic stirring. A reduced pressure of $-350 \pm 10 \mathrm{mmHg}$ was coupled to the distillation system for removing the water. After PLA synthesis, the polymer was dissolved in acetone, precipitated twice in purified water, and dried at $30^{\circ} \mathrm{C}$. This polymer had its chemical composition characterized by Fourier-transform infrared spectroscopy using a Shimadzu IR Prestige-21 spectrometer (Kyoto, Japan) from 4000 to 400 $\mathrm{cm}^{-1}$ in potassium bromide pellets with 32 scans and resolution of 4 $\mathrm{cm}^{-1}$. The viscosity-average molecular weight was recorded by intrinsic viscosity measurement [29] using chloroform as standard.

Suspension of lipid-core nanocapsules was prepared by interfacial deposition of this preformed polymer, as described by Fessi et al. [30,31]. In brief, PLA (100 mg) was dissolved in $20 \mathrm{ml}$ of acetone and $10 \mathrm{ml}$ of ethanol in the presence of Span $60^{\circledR}(80 \mathrm{mg})$ and UA (100 mg). This organic phase was added to the aqueous phase containing $80 \mathrm{mg}$ of Tween ${ }^{\circledR} 80$ and $60 \mathrm{ml}$ of purified water by dripping and under vigorous magnetic stirring at $40^{\circ} \mathrm{C}$. The organic solvent was then evaporated under reduced pressure in a rotary evaporator to the final volume of $10 \mathrm{ml}$. For comparative purposes, a suspension of nanoparticles was prepared with no UA (NPLA-0) as a negative control. All formulations were prepared in triplicate from three independent batches.

The proposed UHPLC-PDA method was used for determining the UA amount in the loaded nanocapsules. The drug quantification was carried out by indirect analysis [17]. The supernatant containing free UA was obtained by ultracentrifugation using an Amicon ${ }^{\circledR}$ device $(M w$ cutoff $=10,000 \mathrm{~g} / \mathrm{mol}$, Merck Millipore, Bedford, MA, USA), was then appropriately diluted in methanol, and analyzed by the aforementioned method. The EE was calculated by the following equation (Eq. 3) in triplicate.

$$
E E=A_{\text {initial }}-\frac{A_{\text {free }}}{A_{\text {initial }}} \times 100
$$

where $A_{\text {initial }}$ is the amount of UA initially added to the formulation and $A_{\text {free }}$ is the concentration of the free drug quantified in the supernatant after ultracentrifugation and suitable dilution.

\section{Statistical analysis}

All data were expressed as mean \pm SD. The linearity data were evaluated by simple linear regression. RSD was shown as required. Data were compared by ANOVA with Tukey's post-hoc test at a significance level of 5\% $(\alpha=0.05)$. GraphPad Prism software version 5.03 (San Diego, CA, USA) was used for statistical analysis.

\section{RESULTS AND DISCUSSION}

Validation method

The method was validated using acetonitrile:water $(92: 8, \mathrm{v} / \mathrm{v})$ as a mobile phase and a flow rate of $0.80 \mathrm{ml} / \mathrm{min}$. The total analysis time and the retention time were 2.1 and $1.78 \mathrm{~min}$, respectively. This fast response is very important for the analysis routine. These conditions also provided a lower tail size and a more symmetrical peak for the UA quantification when compared to other methods that used HPLC [22,23].

The specificity is a validation parameter used for investigating if some particular component of the formulation can interfere in the drug retention time, as well as ensuring that no spikes of other substances or impurities appear in the UA retention time [26]. For this purpose, the UA chromatogram was compared with the chromatogram of nonloaded nanocapsules and no peak was detected at the UA retention time (Fig. 1). This result proved the specificity since there was no interference in the drug retention time. 
Linearity was performed in triplicate in the concentration range from 10 to $100 \mu \mathrm{g} / \mathrm{ml}$. The linear equation achieved was $y=8065.1 x-6096$, where $y$ is the peak area and $x$ is the standard solution concentration in $\mu \mathrm{g} / \mathrm{ml}$. A correlation coefficient of $\mathrm{r}=0.9998$ was recorded, which suggested that the method was linear since an $\mathrm{r}$ value close to 1.0 could indicate the calibration curve suitability [32]

The RSD of the slope was $0.77 \%$, a value lower than that recommend by ICH (5\%) [26]. The negative b value (-6096) was in the $95 \%$ confidence interval of the analytical calibration curve by the ANOVA test. These results are summarized in Table 1.

Although the correlation coefficient value was close to the unit, it does not certainly represent that the method showed a linear relationship. Therefore, it is mandatory to apply the test for a lack of adjustment
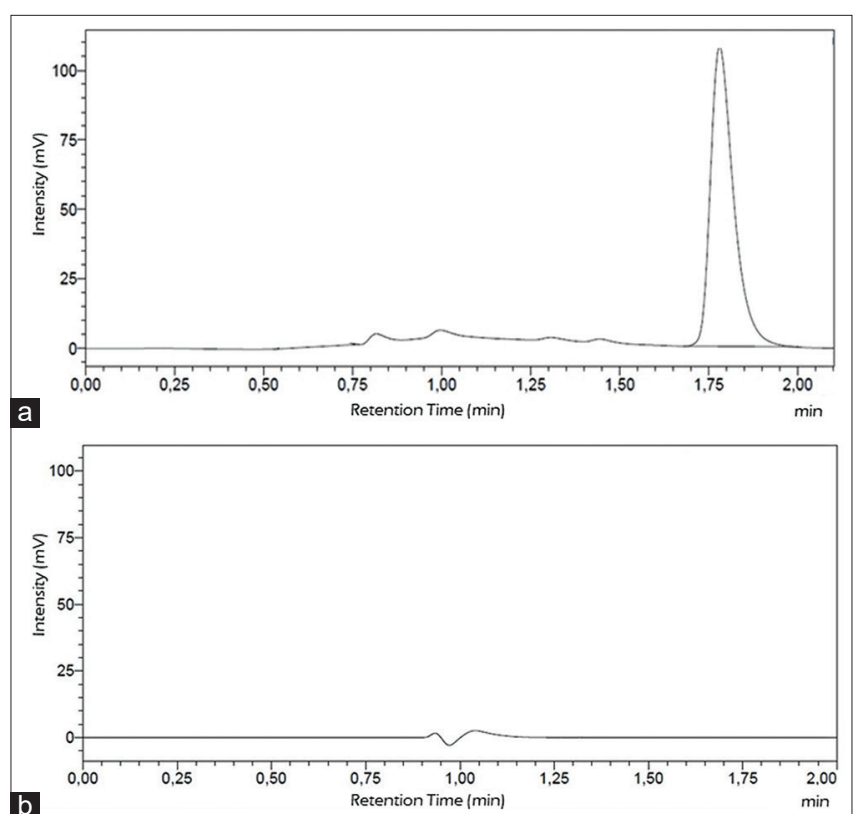

Fig. 1: Representative RP-UHPLC-PDA chromatograms:

(a) Standard UA solution at $60.0 \mu \mathrm{g} / \mathrm{ml}$, (b) non-loaded nanocapsules

Table 1: Linearity parameters of the RP-UHPLC-PDA method for quantifying ursolic acid from lipid-core nanocapsules

\begin{tabular}{ll}
\hline Parameters & Results \\
\hline Linearity & \\
$\quad$ Linear range $(\mu \mathrm{g} / \mathrm{ml})$ & $10.0-100.0 \mu \mathrm{g} / \mathrm{ml}$ \\
$\quad$ Detection limit $(\mu \mathrm{g} / \mathrm{ml})$ & $1.35 \mu \mathrm{g} / \mathrm{ml}$ \\
Quantification limit $(\mu \mathrm{g} / \mathrm{ml})$ & $4.10 \mu \mathrm{g} / \mathrm{ml}$ \\
Regression data* & \\
$\mathrm{n}$ & 3 \\
Slope & $27,762.33$ \\
Standard deviation of slope & 62.36 \\
Relative standard deviation of slope $(\%)$ & 0.77 \\
Intercept $(\mathrm{b})$ & -6096.13 \\
Correlation coefficient $(\mathrm{r})$ & 0.9998 \\
\hline
\end{tabular}

to evaluate the residual values [33]. The $\mathrm{F}$ value obtained for the lack of adjustment was less than the critical $\mathrm{F}$ value for a $95 \%$ confidence interval $(\alpha=0.05)$. Hence, the linearity was confirmed due to the linear regression that did not present a lack of adjustment according to the ANOVA test (Table 2).

The LOD is the lowest concentration in which an analyte can be detected, while the LOQ is the lowest concentration that an analyte can be quantified with acceptable precision and accuracy [34]. Considering the proposed UHPLC-PDA method, the lowest concentration in which UA can be detected (LOD) and quantified (LOQ) was 1.35 and $4.10 \mu \mathrm{g} / \mathrm{ml}$, respectively. These values infer that the background signal does not limit the sensitivity of the UHPLC-PDA peak.

The precision represents the contiguous occurrence of the results obtained from repeated measurements of the same sample [26]. The precision data were expressed as RSD obtained for repeatability and intermediate precision are described in Table 3. All the RSD values were below $5 \%$, which confirm an appropriate precision for the evaluated method [35].

Regarding accuracy, the recovery rate of UA was between 96.16 and $100.30 \%$ for the different concentration levels evaluated. Table 4 describes the obtained data. These results demonstrate that the method is accurate since it is in agreement with the accuracy target limits of $95-105 \%$ [26].

The robustness was based on the RSD values obtained by changing analytical parameters, such as the flow rate, the mobile phase composition, and the column temperature [26]. An analytical method is classified as robust when it remains unchanged at small variations that eventually occur during the analysis process $[26,35]$. The RSD results depicted in Table 5 show that there was no significant difference in the peak area and the UA retention time after the proposed changes. Thereby, the RP-UHPLC-PDA method proved to be robust for analyzing UA even at small changes in chromatographic parameters.

Method applicability: Synthesis of PLA, preparation of ursolic acid-loaded lipid-core nanocapsules, and determination of EE PLA was obtained as a white granular powder by the polycondensation method. The main advantage of polycondensation synthesis arises from the fact that it is a simple process and does not require additional organic solvents, which is essential for polymers that will be used for biomedical purposes [36]. PLA showed the main FTIR bands (Fig. 2) recorded at $3504 \mathrm{~cm}^{-1}$ for the $-\mathrm{OH}$ stretching, at $2995 \mathrm{~cm}^{-1}$ for the $\mathrm{C}-\mathrm{H}$ stretching, at $1759 \mathrm{~cm}^{-1}$ for the $\mathrm{C}=0$ stretching, at $1197 \mathrm{~cm}^{-1}$ for the asymmetric $0-\mathrm{C}=0$ stretching, and at $1093 \mathrm{~cm}^{-1}$ for the symmetrical stretching of the $\mathrm{C}-\mathrm{O}-\mathrm{C}$. These assignments were confirmed by the literature [37].

The obtained polymer showed a viscosity-average molecular weight of $1070 \mathrm{~g} / \mathrm{mol}$, which represents a low molar mass. This value is related to the polycondensation since the water obtained during the esterification causes the hydrolysis of the polyester, which leads to shorter polymer chains. In sequence, the nanocapsules were successfully obtained as nanosuspensions that showed a liquid aspect with a slightly bluish-white opalescent coloring, as typically reported in literature [38]

Table 2: ANOVA results for linearity of the RP-UHPLC-PDA method for quantifying ursolic acid from lipid-core nanocapsules

\begin{tabular}{llllll}
\hline Ursolic acid & SS & DF & MS & F & Fcrit \\
\hline Model & $1126210 \mathrm{E}+12$ & 1 & $1.126210 \mathrm{E}+12$ & 24314.34 & 2.990 \\
Residual & $8800568 \mathrm{E}+08$ & 19 & $4.631878 \mathrm{E}+07$ & Linear & 2.1334 \\
Lack of fit & 380576702 & 5 & 76115340 & No lack of fit \\
Pure error & 499480095 & 14 & 35677150 & 2.307 \\
\hline
\end{tabular}

SS: Sums of squares, DF: Degrees of freedom, MS: Mean squares, F: F value of the test, Fcrit: Critical F value 
Table 3: Repeatability and intermediate precision data of the RP-UHPLC-PDA method for quantifying ursolic acid from lipid-core nanocapsules

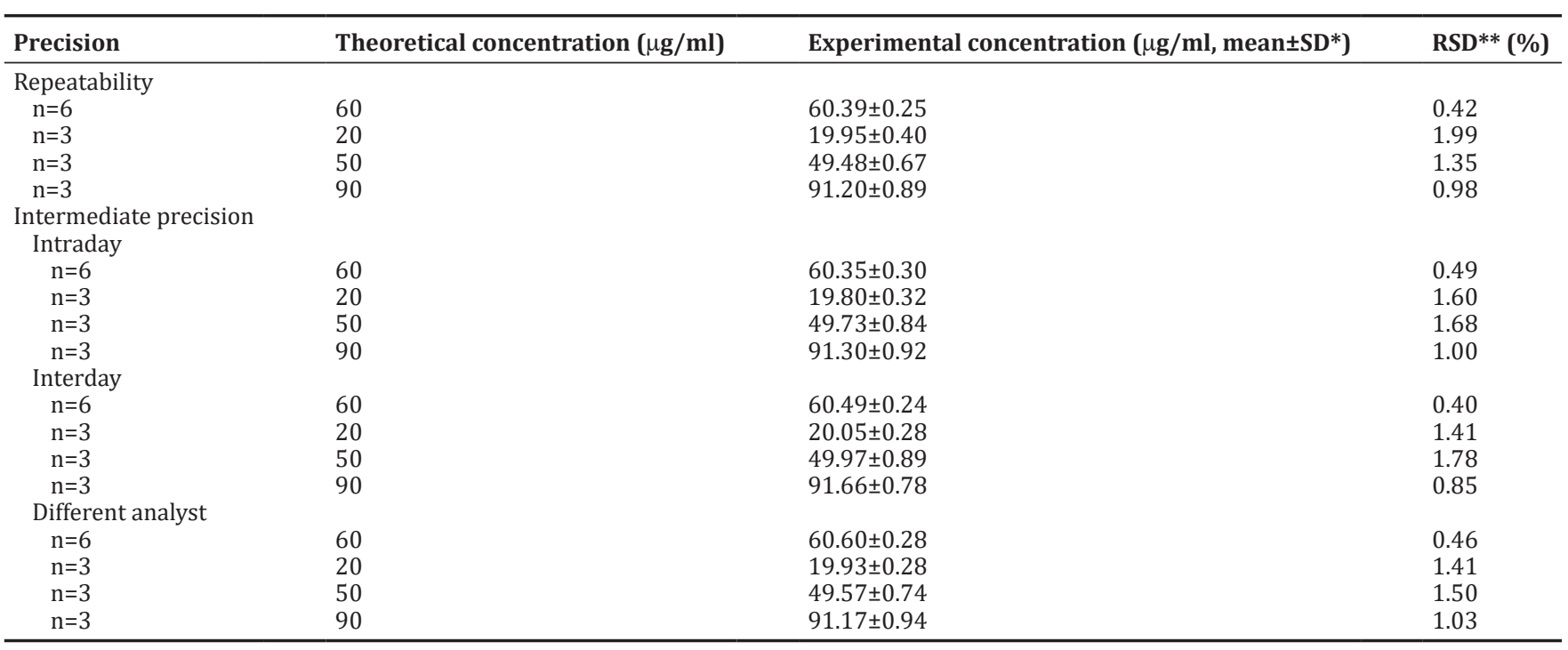

*SD: Standard deviation, **RSD: Relative standard deviation

Table 4: Accuracy data of the RP-UHPLC-PDA method for quantifying ursolic acid from lipid-core nanocapsules

\begin{tabular}{llll}
\hline $\begin{array}{l}\text { Level of } \\
\text { concentration }\end{array}$ & $\begin{array}{l}\text { Final ursolic acid } \\
\text { concentration } \\
(\mu \mathbf{g} / \mathbf{m l})\end{array}$ & SD $\left(\% \pm\right.$ SD $\left.^{*}\right)$ & RSD** (\%) \\
\hline Low & 25 & $100.30 \pm 2.48$ & 2.47 \\
Medium & 55 & $98.60 \pm 2.80$ & 2.84 \\
High & 95 & $96.16 \pm 1.24$ & 1.29 \\
\hline * & Standard deviation $* *$ RSD: & & \\
\hline
\end{tabular}

*SD: Standard deviation, ${ }^{* *}$ RSD: Relative standard deviation

Table 5: Robustness data of the RP-UHPLC-PDA method for quantifying ursolic acid from lipid-core nanocapsules

\begin{tabular}{lll}
\hline Initial parameter & Change & RSD $^{*}$ (\%) \\
\hline Flow rate & $0.75 \mu \mathrm{g} / \mathrm{ml}$ & 1.29 \\
$0.80 \mu \mathrm{g} / \mathrm{ml}$ & $0.85 \mu \mathrm{g} / \mathrm{ml}$ & 1.85 \\
Mobile phase proportion & $91: 9(\mathrm{v} / \mathrm{v})$ & 1.08 \\
$92: 8(\mathrm{v} / \mathrm{v})$ & $93: 7(\mathrm{v} / \mathrm{v})$ & 1.15 \\
Temperature & $48^{\circ} \mathrm{C}$ & 0.54 \\
$50^{\circ} \mathrm{C}$ & $52^{\circ} \mathrm{C}$ & 2.00 \\
\hline
\end{tabular}

*RSD: Relative standard deviation

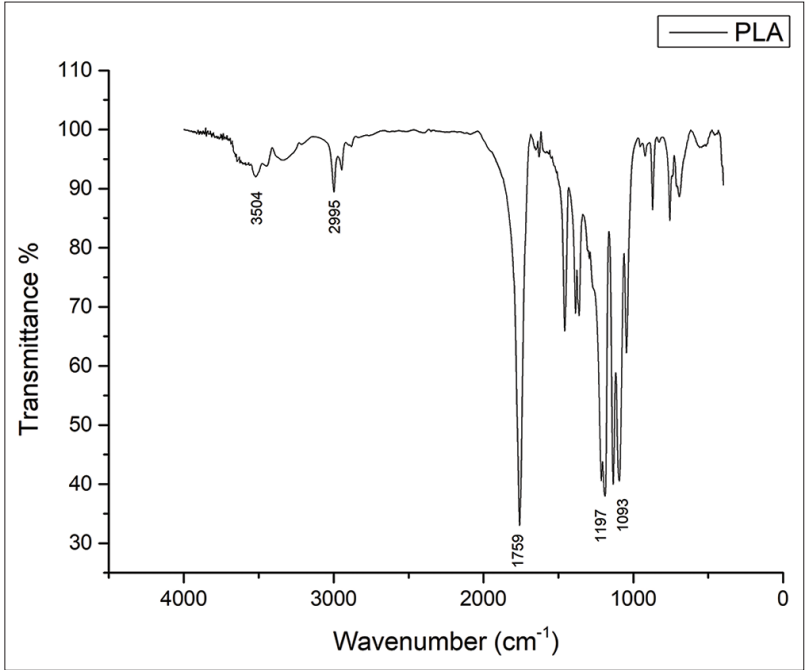

Fig. 2: FTIR spectrum of poly(L-lactic acid)
The previously validated method was then used for the UA quantification from the loaded formulation. The lipid-core nanocapsules presented a suitable EE of $99.89 \pm 0.01 \%$. This value is entirely expected due to the high lipophilicity of the drug (water solubility of $0.102 \mathrm{ng} / \mathrm{l}$ at $25^{\circ} \mathrm{C}$ ) [12], which leads to its high incorporation in the lipid-core of this nanosystem.

\section{CONCLUSION}

The reverse-phase UHPLC-PDA method was developed and validated for quantifying UA from lipid-core PLA nanocapsules. This analytical method is simple, specific, linear, sensitive, precise, accurate, and robust. In addition, it provides advantages over the methods described in the literature since it is fast and easy to apply in the pharmaceutical daily routine of quality control. It requires simple sample preparation, uses a low volume of reagents, shows faster analysis time, and decreases the waste amount, which is very important for the pharmaceutical industry.

\section{ACKNOWLEDGMENT}

The authors would like to thank the Coordination of Improvement of Higher Education Personnel and to the Ministry of Health - Program for the Development of the Industrial Health Complex (PROCIS). To CLABMU-UEPG and UNICENTRO for technical support.

\section{AUTHORS' CONTRIBUTIONS}

Bruna Carletto, Amanda Martinez Lyra, and Paulo Vitor Farago contributed substantially to the concept and study design; Bruna Carletto, Amanda Martinez Lyra, and Rubiana Mara Mainardes performed the data acquisition; Amanda Martinez Lyra, Andressa Novatski, and Bruna Carletto carried out the data analysis/ interpretation; Bruna Carletto and Paulo Vitor Farago drafted the manuscript; Paulo Vitor Farago provided a critical revision of the manuscript for important intellectual content; Adriana Yuriko Koga and Leandro Cavalcante Lipinski were responsible for the statistical analysis; Paulo Vitor Farago performed the supervision; all authors read and approved the final manuscript.

\section{CONFLICTS OF INTEREST}

The authors declare that there are no conflicts of interest.

\section{AUTHORS' FUNDING}

The authors did not receive any funding for the present paper. 


\section{REFERENCES}

1. Xiang L, Chi T, Tang Q, Yang X, Ou M, Chen X, et al. A pentacyclic triterpene natural product, ursolic acid and its prodrug US597 inhibit targets within cell adhesion pathway and prevent cancer metastasis. Oncotarget 2015;6:9295-312

2. Mlala S, Oyedeji AO, Gondwe M, Oyedeji OO. Ursolic acid and its derivatives as bioactive agents. Molecules 2019;24:2751.

3. Woủniak Ł, Skąpska S, Marszałek K. Ursolic acid-a pentacyclic triterpenoid with a wide spectrum of pharmacological activities. Molecules 2015;20:20614-41.

4. López-Hortas L, Pérez-Larrán P, González-Muñoz M, Falqué E, Domínguez $\mathrm{H}$. Recent developments on the extraction and application of ursolic acid. A review. Food Res Int 2018;103:130-49.

5. Sundaresan A, Harini R, Pugalendi KV. Ursolic acid and rosiglitazone combination alleviates metabolic syndrome in high fat diet fed C57BL/6J mice. Gen Physiol Biophys 2012;31:323-33.

6. Gutiérrez-Rebolledo GA, Siordia-Reyes AG, Meckes-Fischer M, Jiménez-Arellanes A. Hepatoprotective properties of oleanolic and ursolic acids in antitubercular drug-induced liver damage. Asian Pac J Trop Med 2016;9:644-51.

7. Singh AK, Pandey H, Ramteke P, Mishra SB. Nano-suspension of ursolic acid for improving oral bioavailability and attenuation of Type II diabetes: A histopathological investigation. Biocatal Agric Biotechnol 2019;22:101433-43.

8. Ramos-Hryb AB, Pazini FL, Kaster MP, Rodrigues AL. Therapeutic potential of ursolic acid to manage neurodegenerative and psychiatric diseases. CNS Drugs 2017;31:1029-41.

9. Checker R, Sandur SK, Sharma D, Patwardhan RS, Jayakumar S, Kohli $\mathrm{V}$, et al. Potent anti-inflammatory activity of ursolic acid, a triterpenoid antioxidant, is mediated through suppression of NF-KB, AP-1 and NF-AT. PLoS One 2012;7:e31318.

10. Gai W, Yu D, Wang X, Wang P. Anti-cancer effect of ursolic acid activates apoptosis through ROCK/PTEN mediated mitochondrial translocation of cofilin-1 in prostate cancer. Oncol Lett 2016;12:2880-5.

11. Chan EW, Soon CY, Tan JB, Wong SK, Hui YW. Ursolic acid: An overview on its cytotoxic activities against breast and colorectal cancer cells. J Integr Med 2019;17:155-60.

12. Zhang C, Wang C, Li W, Wu R, Guo Y, Cheng D, et al. Pharmacokinetics and pharmacodynamics of the triterpenoid ursolic acid in regulating the antioxidant, anti-inflammatory, and epigenetic gene responses in rat leukocytes. Mol Pharm 2017;14:3709-17.

13. Nahak P, Karmakar G, Chettri P, Roy B, Guha P, Besra SE, et al. Influence of lipid core material on physicochemical characteristics of an ursolic acid-loaded nanostructured lipid carrier: An attempt to enhance anticancer activity. Langmuir 2016;32:9816-25.

14. Biswas S, Mukherjee PK, Harwansh RK, Bannerjee S, Bhattacharjee P. Enhanced bioavailability and hepatoprotectivity of optimized ursolic acid-phospholipid complex. Drug Dev Ind Pharm 2019;45:946-58.

15. Asai T. Nanoparticle-mediated delivery of anticancer agents to tumor angiogenic vessels. Biol Pharm Bull 2012;35:1855-61.

16. Yamamoto E, Miyazaki S, Aoyama C, Kato M. A simple and rapid measurement method of encapsulation efficiency of doxorubicin loaded liposomes by direct injection of the liposomal suspension to liquid chromatography. Int J Pharm 2018;536:21-8.

17. Nadal JM, Toledo MG, Pupo YM, Paula JP, Farago PV, Zanin SM. A stability-indicating HPLC-DAD method for determination of ferulic acid into microparticles: Development, validation, forced degradation, and encapsulation efficiency. J Anal Methods Chem 2015;2015:1-10.

18. Lü H, Lee R, Huang J, Chen J, Go VW, Li Z, et al. A new HPLC-UV method for the quantification of terpenoids and antioxidant activity of commercial loquat leaf tea and preparation. J Food Meas Charact 2020;14:1085-91.

19. Owczarek A, Kuüma Ł, Wysokińska H, Olszewska M. Application of response surface methodology for optimisation of simultaneous UHPLC-PDA determination of oleanolic and ursolic acids and standardisation of ericaceae medicinal plants. Appl Sci 2016;6:244-61

20. Stebounova L, Ebert SM, Murry LT, Adams CM, Murry DJ. Rapid and sensitive quantification of ursolic acid and oleanolic acid in human plasma using ultra-performance liquid chromatography-mass spectrometry. J Chromatogr Sci 2018;56:644-9.

21. Zheng Z, Zhao X, Zhu S, Dang J, Qiao X, Qiu Z, et al. Simultaneous determination of oleanolic acid and ursolic acid by in vivo microdialysis via UHPLC-MS/MS using magnetic dispersive solid phase extraction coupling with microwave-assisted derivatization and its application to a pharmacokinetic study of Arctium lappa L. Root extract in rats. J Agric Food Chem 2018;66:3975-82.

22. Antonio EA, Junior OR, Khalil NM, Mainardes RM. A validated HPLC-PDA method for the analysis of ursolic acid content in poly (lactic acid) nanoparticles. Curr Chromatogr 2016;3:117-22.

23. Almeida MM, Bou-Chacra NA, Tavares VF, Baby AR, Kaneko TM, Velasco MV. Determination of ursolic acid from polymeric nanoparticles using high-performance liquid chromatography method. Lat Am J Pharm 2012;8:1187-91.

24. Baishya R, Nayak DK, Kumar D, Sinha S, Gupta A, Ganguly S, et al. Ursolic acid loaded PLGA nanoparticles: In vitro and in vivo evaluation to explore tumor targeting ability on b16f10 melanoma cell lines. Pharm Res 2016;33:2691-703.

25. Chesnut S, Salisbury JJ. The role of UHPLC in pharmaceutical development. J Sep Sci 2007;30:1183-90.

26. The International Conference on Harmonization of Technical Requirements for Registration of Pharmaceuticals for Human Use. Validation of Analytical Procedures: Text and Methodology Q2 (R1); 2005.

27. Chen G, Kim H, Kim E, Yoon J. Synthesis of high-molecular-weight poly (L-lactic acid) through the direct condensation polymerization of L-lactic acid in bulk state. Eur Polym J 2006;42:468-72.

28. Hyon S, Jamshidi K, Ikada Y. Synthesis of polylactides with different molecular weights. Biomaterials 1997;18:1503-8.

29. Horváth T, Szabó TJ, Marossy K. Molar mass determination of microwave initiated polycondensation produced PLLA by capillary viscometry method. J Phys 2020;1527:12-9.

30. Fessi H, Puisieux F, Devissaguet JP, Ammoury N, Benita S. Nanocapsule formation by interfacial polymer deposition following solvent displacement. Int J Pharm 1989;55:R1-4

31. Rudnik LA, Farago PV, Budel JM, Lyra A, Barboza FM, Klein T, et al. Co-loaded curcumin and methotrexate nanocapsules enhance cytotoxicity against non-small-cell lung cancer cells. Molecules 2020;25:1913.

32. Justus B, Kanunfre CC, Budel JM, de Faria MF, Raman V, de Paula JP. New insights into the mechanisms of French lavender essential oil on nos-small-cell lung cancer cell growth. Ind Crops Prod 2019;136:28-36.

33. Almeida MA, Nadal JM, Klein T, de Paula JP, Budel JM, Novatiski A, et al. Innovative phytoformulation containing capsaicinoids: Microparticles development, analytical method validation, and antiulcer effect. Pharmacogn Mag 2018;14:290-6.

34. Gaspar MD, Lyra AM, Camargo GA, Nadal JM, Teitelbaum AP, dos Santos FA, et al. Development and validation of a reversed-phase UHPLC-PDA method for determination of chlorhexidine in meth (acrylic) nanocapsules. Lat Am J Pharm 2020;39:792-8.

35. Lopes CE, Langoski G, Klein T, Ferrari PC, Farago PV. A simple HPLC method for the determination of halcinonide in lipid nanoparticles: Development, validation, encapsulation efficiency, and in vitro drug permeation. Braz J Pharm Sci 2017;53:1-9.

36. Ghalia MA, Dahman Y. Biodegradable poly (lactic acid)-based scaffolds: Synthesis and biomedical applications. J Polym Res 2017;24:1-22.

37. Moazzen N, Khanmohammadi M, Garmarudi AB, Kazemipour M, Dogaheh MA. Optimization and infrared spectrometric evaluation of the mechanical properties of PLA-based bio-composites. J Macromol Sci A 2019;56:17-25.

38. Carletto B, Berton J, Ferreira TN, Dalmolin LF, Paludo KS, Mainardes RM, et al. Resveratrol-loaded nanocapsules inhibit murine melanoma tumor growth. Colloids Surf B Biointerfaces 2016;144:65-72. 